\title{
Preface: the concept and consequences of multidrug resistance
}

\author{
Jonathan A. Sheps • Victor Ling
}

Received: 28 April 2006 / Accepted: 7 June 2006 / Published online: 22 July 2006

(C) Springer-Verlag 2006

\begin{abstract}
The problem of multidrug resistance (MDR) in human cancers led to the discovery 30 years ago of a single protein P-glycoprotein (P-gp), capable of mediating resistance to multiple structurally diverse drugs. P-gp became the archetypal eukaryotic $\mathrm{ABC}$ transporter gene, and studies of P-gp and related $\mathrm{ABC}$ transporters in both eukaryotes and bacteria have led to a basic mechanistic understanding of the molecular basis of MDR. Particular milestones along the way have been the identification of the homology between P-gp and bacterial transport proteins, the purification and functional reconstitution of P-gp into synthetic lipid systems, and the development of targeted therapies that attempt to overcome MDR by inhibiting Pgp. This preface places into this context some of the less well-explored themes developed in the MDR field, particularly various alternative models of P-gp action, evidence for parallel physiological roles for P-gp, and the unusual relationship between the substrate recognition capabilities of $\mathrm{ABC}$ transporters and their evolutionary history.
\end{abstract}

Keywords ATP hydrolysis - ATP release $\cdot$ Blood-brain barrier . Cancer cells · Cell culture - Chloride channel . Intracellular $\mathrm{pH} \cdot \mathrm{Membrane}$ transport

It has been 30 years since the discovery of P-glycoprotein (P-gp) and its association with the phenomenon of multidrug resistance (MDR). For a historical account of its discovery and the more important milestones in the P-gp field, see personal reflections by Gottesman and Ling [19]. Complementary to this, in this preface we touch on some of

\footnotetext{
J. A. Sheps $\cdot$ V. Ling $(\triangle)$

BC Cancer Research Centre,

675 West 10th Avenue,

V5Z 1L3 Vancouver, British Columbia, Canada

e-mail: vling@bccrc.ca
}

the less widely-discussed discoveries that led to our current understanding of MDR in mammalian cells and its role in the wider context of membrane biology. The impetus for the research was the concept that an understanding of MDR is necessary to inspire better therapies for multidrug resistant cancers, which may account for up to half of all cancer-related deaths.

\section{"Resistance follows chemotherapy as a faithful shadow"-Paul Ehrlich}

The problem of antibiotic resistance arose simultaneously with the discovery of antibiotics themselves. DDT-resistant insects were found within a year of its introduction [17]. When alternative insecticides were used, the selection with the new agents produced cross-resistance to DDT [3], just as DDT had fostered cross-resistance to the centuries-old agent pyrethrum [72]. Multiple-resistant bacteria first became apparent in the 1960s [65] and when combination chemotherapy for resistant cancers was introduced in 1963 [26], cross-resistant tumours followed, with cross-resistant cell lines described shortly after [5]. It is inevitable that organisms adapt to efforts to control them. What multidrug resistance has made obvious is that organisms as a rule do not evolve specific responses but mobilise pre-existing, broad defence mechanisms that 'anticipate' moves against them.

We encountered the MDR problem in our own work when we used single-step selections to isolate cells resistant to the microtubule polymerisation inhibitor colchicine $\left(\mathrm{CH}^{\mathrm{R}}\right)$, hoping to obtain tubulin mutants with cell division defects. Highly resistant lines of Chinese hamster ovary cells were selected from clonal populations of lower resistance. The $\mathrm{CH}^{\mathrm{R}}$ cells all had pleiotropic cross-resistance to 
drugs such as daunomycin and puromycin, not known to interact with microtubules, and all had reduced colchicine uptake while the colchicine binding ability of cell extracts was not reduced. We concluded that colchicine-resistance probably arose from reduced permeability [39]. After we submitted that paper, Keld Danø submitted a study of the kinetics of daunomycin uptake in Ehrlich ascites tumour cells [12], showing that daunomycin reached lower steady-state levels in resistant, compared to sensitive, cells while uptake into isolated nuclei was similar. Moreover, daunomycin accumulation was increased by metabolic inhibitors such as 2-deoxyglucose and structural analogues such as $N$-acetyldaunomycin as well as in the presence of Vinca alkaloids to which the cells were also resistant. These observations led Danø to conclude that the reduced accumulation of drugs must be due to an energy-dependent, carrier-mediated extrusion mechanism and that the Vinca alkaloids competed with daunomycin for the extrusion mechanism.

Our results were consistent with Danø's conclusions, but we felt at the time that the highly pleiotropic MDR phenotype (i.e. cross-resistance to unrelated drugs and increased or collateral sensitivity to many membrane active agents [4]) could not be explained easily by a classical drug efflux mechanism. At the same time, our study of initial rates of colchicine uptake provided evidence that colchicine enters cells by unmediated diffusion. For example, colchicine uptake could not be competed with the close structural analogue colcemid. 'Fluidisers' of the membrane lipid bilayer such as non-ionic detergents and local anaesthetics also stimulated drug uptake and reversed drug resistance $[6,39]$. To us, this suggested a global effect on the cell membrane, an 'active' permeability barrier model, hence the initial suggestion that MDR could result from a 'modulator' of membrane lipid fluidity, perhaps involving a change in the phosphorylation state of membrane proteins $[6,37]$.

\section{P-glycoprotein and the search for a central dogma of MDR}

By the 1970s, mammalian somatic cell genetics had advanced to where cell lines could be readily manipulated in laboratory culture and classical techniques like LuriaDelbrück fluctuation analyses could verify that variants appeared at rates consistent with spontaneous mutation. The transfer of novel phenotypes to recipient cells by chromosome transfer or DNA transfection could be evidence for a phenotype having a genetic basis. Cell hybridisation showed that the MDR phenotype paralleled the $\mathrm{CH}^{\mathrm{R}}$ phenotype in being incompletely dominant [38, 39]. Independent revertant clones, selected in a single step from two highly resistant lines, showed that MDR and $\mathrm{CH}^{\mathrm{R}}$ phenotypes co-reverted [37]. This genetic data pointed to a single change or a small set of linked changes responsible for the MDR phenotype. By labelling cell-surface carbohydrates, we first found a prominent $\mathrm{CH}^{\mathrm{R}}$-specific $165-\mathrm{kDa}$ peak, greatly reduced in revertant cells [27]. We later isolated plasma membrane vesicles (PMVs) from $\mathrm{CH}^{\mathrm{R}} \mathrm{C} 5$ cells and found a protein visible as a Coomassie-bluestained band at about $170 \mathrm{kDa}$, less prominent in less resistant cells and absent or barely detectable in wild-type or revertant cells [43]. We called this P-glycoprotein because of its presumed association with colchicine permeability. P-gp localised to the plasma membrane and was present in significant amounts $(3-4 \%$ of total plasma membrane protein) in a highly colchicine-resistant line. This work made possible in vitro studies of P-gp function in isolated PMVs, the raising of antisera, and eventually the purification and reconstitution of P-gp.

We were not the only ones who initially found it difficult to accept P-gp as causing the entire pleiotropic MDR phenomenon by directly interacting with each and every substrate. It seemed more plausible, initially, that P-gp recruited the cellular factors necessary to fully explain MDR. Our acceptance of the idea that P-glycoprotein itself could function as an efflux pump with a surprisingly broad specificity came about with the recognition [18] that P-gp was a eukaryotic homologue of a multifunctional family of transport proteins in bacteria [22], what came to be called the ABC transporters. The close similarity of the P-gp sequence with the hemolysin $\mathrm{B}$ (HlyB) transport protein caused us to formulate a functional model of P-gp as a multidrug efflux pump. While most $\mathrm{ABC}$ transporters have roles importing substrates into bacteria, those in eukaryotes function exclusively as exporters, moving substrates from the ATP-rich cytosol out of cells or into intracellular organelles [48].

During the 1980s and 1990s, many were searching for alternative models of P-gp activity other than a direct active transporter interacting with every single drug an MDR cell line resists. A number of possibilities were proposed that might explain the several phenomena of multidrug resistance in terms of a single change in the state of the cell. The various 'indirect' models often postulated that P-gp carried out a single activity, altering a physiological parameter to which all P-gp-active drugs would respond due to some shared property. As MDR drugs are typically cationic amphiphiles, changes in membrane properties or in voltage or $\mathrm{pH}$ gradients across the membrane have the potential to form a general permeability barrier; though resistance to neutral or anionic P-gp substrates would remain unexplained. P-gp could function to alter membrane fluidity, either by its own insertion in the membrane or as a transporter for a single species of membrane lipid or by acting as a chloride channel to change the cellular $\mathrm{pH}$ [45]. Other 
indirect models argue that P-gp transports a single core compound and all substrates interact directly with that compound, so that P-gp need not take account of their differences. These models include: suggestions that P-gp transports ATP, with drugs forming complexes with ATP allowing co-transport [1], or that drugs are transported as sulphate conjugates with the problem of multiple specificity referred to a multiplicity of drug-metabolising enzymes [78].

The finding that a molecule similar to P-gp was an exporter [18] does not prove that P-gp is also one, and as HlyB has only a single natural substrate it left the problem of a single transporter capable of recognising multiple substrates unanswered. A subsequent investigation into substrate recognition by $\mathrm{HlyB}$, however, demonstrated a deep functional similarity between it and P-gp that made a direct efflux model of P-gp more plausible. The natural substrate for HlyB is the cytolytic toxin hemolysin A (HlyA), recognised by HlyB by virtue of a signal sequence comprising the C-terminal 60 amino acids of HlyA [32]. We demonstrated that this signal could be replaced by an entirely dissimilar, though homologous, sequence from the leukotoxin (LktA) of Bordetella pertussis. Both signals are predicted to form similar charged and amphiphilic secondary structures [74]. Biochemical experiments showed that the signal sequences, known to interact with the transporter [60], formed amphiphilic helices only in the presence of lipids. This suggested that HlyB might recognise its substrate within the inner leaflet of the membrane [76]. We were eventually able to replace the HlyA signal entirely with random synthetic sequences and showed that only a resemblance to the native signal in charge and amphiphilicity, not in primary sequence, was required [24]. HlyB, with only a single natural substrate, possesses an attribute of multidrug transporters: recognition of a wide variety of substrates in the context of the membrane. HlyB is therefore pre-adapted to recognise substrates that share certain biophysical properties, membrane activity chief among them. The implication is that peptide transporters like HlyB would be perfect ancestors for MDR genes such as P-glycoprotein.

This impression was reinforced by genetic experiments in which mutant HlyA signal sequences were used to isolate complementing second-site mutations in HlyB. These HlyB mutants have allele-specific effects on the recognition of HlyA signal variants [60, 75], suggesting that all transport-competent signals physically interact with a site on HlyB that recognises signal sequences using redundant, partially overlapping amino acid contacts. A transporter requiring only a subset of possible interactions, able to recognise variations on a theme, is what one expects of a multidrug transporter. Drug recognition by P-gp may be analogous to HlyB selectively binding a few amino acids out of a larger peptide, and indeed many membrane-active antibiotic peptides are also P-gp substrates [31, 59].

\section{The transport mechanism(s) of $\mathrm{ABC}$ transporters}

During the early 1990s, Adam Shapiro and others were engaged in a major effort to purify, reconstitute, and investigate the properties of P-gp in an entirely artificial lipid environment [52, 54-58, 68]. Shapiro's work demonstrated unequivocally the competence of P-gp alone to directly catalyse the efflux of multiple drugs from the lipid bilayer of the plasma membrane. P-gp has at least three distinct drug binding sites [53], with allosteric interactions, both positive and negative, between them. Whether these interactions reflect modulation of a common function in the transporter or drug molecules interacting with one another within a common binding pocket remains to be fully explored.

This system has also been used to demonstrate that P-gp can recognise some substrates specifically within the inner leaflet of the membrane [10], which is an observation consistent with either a 'flippase' model [21] or a transporter model, though in either case a direct and specific interaction between P-gp and its substrates is implied. It is possible that P-gp acts as a flippase for some substrates that have a strong affinity for the bilayer, such as phospholipids, and as a transporter for substrates where removal entirely from the membrane is energetically favourable. P-gp could then be seen as having a single biochemical mechanism for driving transport of all its substrates whether they are 'transported' or 'flipped'.

Experiments trapping P-gp in particular stages of the ATP-binding/hydrolysis/ADP+Pi-release cycle [50] point to a model [23] whereby the apo-transporter has the highest affinity for drug binding. Drug binding stimulates ATP binding, powering transport, followed by ATP hydrolysis to reset the machinery. Typical measured stoichiometries suggest one ATP is hydrolysed per drug molecule transported, which makes it likely that P-gp transport two drug molecules at a time in a concerted action [51], which may be why binding drug to one site on P-gp not infrequently can stimulate transport of drugs bound to another site $[53,56]$.

The highly hydrophobic substrates of P-gp would be expected to accumulate at high local concentrations in the lipid bilayer, owing to their membrane affinity and the membrane's tiny volume. It follows that the $K_{\mathrm{m}}$ for P-gp binding these compounds could be quite high $[52,55]$ and this may be an important feature, allowing P-gp's interaction with substrates to be looser, less sterically precise than is typical of enzymes. This looseness of fit creates a space in which multiple near-matching compounds can be 
accommodated and accepted while retaining a high turnover rate

Breakthroughs in crystallisation of bacterial membrane proteins have recently led to a proliferation of highresolution $\mathrm{ABC}$ transporter structures (reviewed in [20]). Of particular interest are structures of the MsbA proteins of Escherichia coli [9], Vibrio cholerae and Salmonella typhimurium [42]. This series appears to have captured a molecule functionally similar to P-gp in stages analogous to those predicted by the biochemical models for the ATPdrug transport cycle [13]. These show a protein with a large, water-filled, substrate-binding cavity that reorients upon ATP binding to open to the extracellular space. Also notable is an open groove along one side of the bundle of transmembrane domains, allowing the native substrate of MsbA, a glycolipid, to remain partially embedded in the membrane while its hydrophilic head group is moved from one aqueous interface to the other. The lipid chains rotate $180^{\circ}$ as they 'flip' from the inner to the outer leaflet, quite as literally as the term 'flippase' implies. MsbA, with an essential physiological role in transporting a component of the Gram-negative outer cell membrane does have multidrug transport capacity overlapping the MDR phenotype of other bacterial ABC transporters, such as LmrA of Lactococcus lactis [41, 69]. There are typically several multidrug transporters in bacterial genomes, most not members of the ATP-binding cassette superfamily but instead secondary transporters (powered by $\mathrm{H}+$ gradient, not ATP) sharing with $\mathrm{ABC}$ transporters the characteristic of a dozen or so transmembrane domains. Structural studies of secondary MDRs [73] suggest they bind multiple drugs following the same principles elucidated in $\mathrm{ABC}$ transporters, recognising substrates within the lipid bilayer using a large internal drug binding site that can accommodate at least two substrate molecules, possibly allowing interactions between bound substrates. With all these MDR proteins to choose from, why would a single-cell organism retain so many of them? There may be distinct preferences and patterns of drug resistance that best suit particular environments or particular threats that occur often enough for selection to maintain a specialised transporter for them, but there are suggestions that multiple transporters are maintained as a side effect of the physiological roles MDR proteins play. LmrA, for example, functions as a $\mathrm{H}+/ \mathrm{K}+$ antiporter, as well as an MDR protein, and the $\mathrm{H}+/ \mathrm{K}+$ transport activity has a role in $\mathrm{pH}$ tolerance [33].

\section{If you are not part of the solution, you are part of the membrane}

The speed with which P-gp moves substrates across (or out of) membranes is crucial. In determining whether a cell is resistant to a given compound, it may indeed be necessary to consider the membrane and the transporter(s) as a functionally integrated unit. Equilibrium dialysis experiments by Eytan et al. [15] measured the affinity of hydrophobic molecules for lipid vesicles, correlated with their interactions with P-gp. They found that membrane affinity was not the deciding factor in determining a P-gp substrate but rather the speed at which a substrate migrated across the membrane. Slowly permeating molecules can be excluded from the cell by P-gp, whereas those permeating rapidly act as P-gp inhibitors, if they interact with P-gp at all. The classic example is verapamil, an excellent P-gp substrate that re-crosses the membrane so rapidly after being effluxed that it acts as a competitive inhibitor of P-gp. This suggests that a major selective pressure on P-gp or any MDR system built on similar principles is not only meeting the challenge of recognising all necessary substrates but also ignoring those which will waste energy in futile transport cycles. The latter may be a greater challenge, responsible for the collateral sensitivity to drugs sometimes seen in MDR cell lines [4, 30]. In retrospect, it appears somewhat naïve to have assumed that the membrane functions either as a passive barrier to drugs or no barrier at all, leaving P-gp alone with the task of selecting drugs to exclude. It is now clear that the membrane is a highly selective determinant of the way in which substrates are presented to P-gp. The lipid composition of the membrane and the mix of proteins in it may determine to a large extent whether a given P-gp/drug pairing will result in successful transport and whether transport of that compound will be protective of or destructive to the cell. The dependence on the membrane as the environment in which P-gp recognises its substrates also explains why compounds altering membrane fluidity affect P-gp function, even if they do not interact with P-gp directly [40]. Membrane changes may perturb either the structure of P-gp or the conformation of the drug, changing its recognition by P-gp or sequester drugs into a membrane subdomain from which P-gp is excluded. Changes in membrane dynamics might allow drugs to cross the membrane more rapidly than P-gp can efflux them, subverting resistance [29]. The critical parameter for determining whether a cell resists a drug is not the extracellular concentration of drug but the intracellular concentration set by the equilibrium between drug permeation through the membrane and efflux by all the cell's competent transporters.

We envision cells as being something like rain barrels, which may fill with hydrophobic compounds to the level permitted by whichever $\mathrm{ABC}$ transporter in the cell has the lowest $K_{\mathrm{m}}$ for that particular compound. This model was first evoked to explain the enterohepatic circulation of bile salts in mutant mice. When the major bile salt transporter is inactivated, an alternative bile salt transporter (P-gp!) with a 
lower affinity (higher $K_{\mathrm{m}}$ ) for bile salts comes into play [34, 35]. Thus, if the level of accumulated hydrophobic compound is not toxic, the cell survives, but if the transporter is removed or inhibited, other transporters, whether already present or upregulated in response to the loss of the first, may come into play. The concentration of the compound then rises to a level nearer the $K_{\mathrm{m}}$ of the transporter with the next highest affinity. One prediction of this model is that the cells may suffer toxicity even in the presence of substantial ABC-transporter-mediated efflux if the $K_{\mathrm{m}}$ for the substrate is higher than the threshold toxicity for that compound in that cell. The dependence of P-gp on particular regulators of cell membrane structure [79], the effect of P-gp overexpression on the structure of the membrane [2], and the possible autocrine functions of P-gp in cell growth and survival [44] are still debated.

\section{Evolution of MDR}

The rather peculiar substrate recognition characteristics of multidrug transporters could have arisen in a transporter with a more limited initial function, probably transporting peptides or some, more limited, set of hydrophobic compounds. The $\mathrm{ABC}$ transporter family in eukaryotes has been subdivided, on the basis of primary sequence similarity and domain organisation into eight subfamilies (A-H) of which P-gp and HlyB are members of subfamily B. A phylogeny [61] of $\mathrm{ABC}$ transporters from four completely sequenced eukaryote genomes (yeast, Drosophila, Caenorhabditis elegans and human) confirms this division and reveals that the MDR function has evolved at least three times independently among $\mathrm{ABC}$ transporters found in the human genome (Fig. 1) and probably at least four times if one includes the pleiotropic drug resistance family of proteins, members of subfamily $\mathrm{G}$ with a 'full transporter' pseudo-dimer configuration, found so far only in plant [11] and fungal [28] genomes. Though animal genomes contain roughly the same numbers of $\mathrm{ABC}$ transporters, there are relatively few orthologous pairs of transporters shared between phyla. This is even more marked in subgroups associated with multidrug resistance (particularly the MRPs and P-glycoproteins). In these gene families, genes have frequently been lost and then regained through gene duplication events. This is reminiscent of an evolutionary pattern termed 'dynamic coherence' [25], thought to characterise the evolution of gene families that are not highly conserved. Highly conserved gene families usually consist of essential genes with specialised roles and are retained in all kingdoms. Orthologous $\mathrm{ABC}$ transporters are strongly conserved at the primary sequence level but distributed rather more patchily than one would expect for proteins with critical functions. We hypothesised [61] that the substrate recognition flexibility that characterises $\mathrm{ABC}$ transporters has resulted in this atypical evolutionary pattern. The regular occurrence of multiple $\mathrm{ABC}$ transporters able to transport the same substrate renders most single gene losses tolerable, as confirmed by the observation that $\mathrm{ABC}$ transporter knockout organisms usually have subtle phenotypes. The loose fit between substrate and transporter may conversely help preserve novel ABC transporters originating by gene duplication. Novel ABC proteins can rapidly specialise, with few mutations necessary to shift substrate specificity without completely removing the original function. $\mathrm{ABC}$ genes may also multiply by gene duplication followed by 'subfunctionalisation' rather than by 'neofunctionalisation'. The expression patterns of $\mathrm{ABC}$ transporters in C. elegans [77] suggest that recently duplicated clusters of P-gps display divergent tissue expression patterns, possibly without any real change in transport specificity. Specialisation at the tissue level rather than function may explain why C. elegans has 15 P-gps, compared to four in humans [counting the bile salt export pump (BSEP or ABCB 11) and ABCB5 as P-gps, which they would be in the worm], though one could equally argue that, as soil organisms, these worms live in a more toxic environment, with less behavioural control over their exposures than either humans or Drosophila. This question can be answered once the balance of drug resistance vs physiological function is evaluated for the complete range of transporters present in each genome.

\section{Physiological roles of multidrug transporters}

It seems clear that P-gp can act alone as a multidrug transporter, but it is likely that P-gp and other MDRs also have normal physiological roles in the absence of toxic challenges. P-gp knockout mice are healthy, unless exposed to those drugs to which they have enhanced sensitivity [49]. P-gp may contribute to normal physiology through transport of less critical substrates or as a co-transporter for substrates that also have other transporters, so the absence of P-gp would only be noticed under unusual physiological stress. In Sister of P-glycoprotein (Spgp, the mouse orthologue of BSEP) knockout mice defective for the major bile acid transporter in liver, there is a marked upregulation of P-glycoprotein genes, which may be adaptive, inasmuch as P-gp has been shown in vitro to transport bile acids $[34,71]$.

The physiological function of P-gp should not be dichotomised as protecting cells against external toxins vs secreting an endogenous compound. The cells in one tissue may need protection against normal secretions used elsewhere, so that resisting endogenous compounds may be as critical as secreting them. P-gp may do both in 


\section{Key to Domain Organisation}

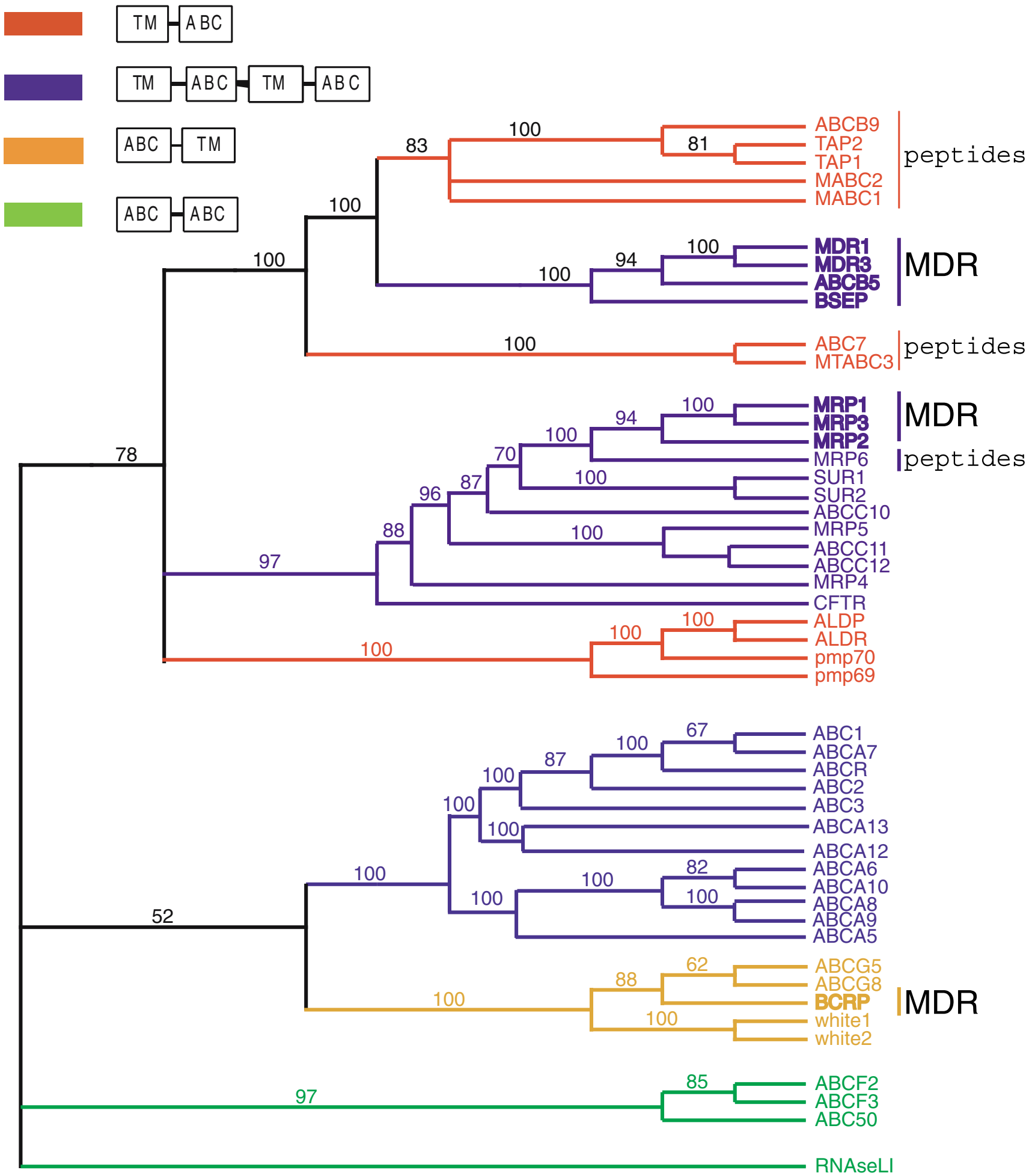

Fig. 1 MDR capacity has evolved multiple times among $A B C$ transporters. The phylogenetic tree shows all human $\mathrm{ABC}$ transporters, with branches coloured according to their characteristic domain structure (inset shows the colour key). TM, transmembrane domain; $A B C$, ATP-binding cassette. Names in bold indicate those conferring MDR phenotypes. Image adapted from Figs. 1 and 2 of [61] 
different tissues, being involved in the secretion of steroid hormones from the adrenal glands [66], and may also provide the brain with much-needed hormone independence $[16,67]$. Drugs that act on the brain will have their bioavailability modulated by MDR systems that are part of the blood-brain barrier [62] and individual variation in the pharmacology of these compounds, particularly their effects on the brain and liver, will depend on individual variation in P-gp expression and function. We cannot discount the possibility that additional roles have been overlooked.

A similarly ambiguous set of roles is apparent for $\mathrm{ABC}$ transporters in bacteria. An example is the cell-cell signalling systems, so-called quorum sensing systems, whereby bacteria measure their own population densities and regulate their activities accordingly, typically by reducing their growth rate. Several quorum-sensing signals are transported by MDR systems, at least in Pseudomonas aeruginosa [47]. Quorum sensing mediates cooperation among cells that also compete with one another, and correct secretion (or resistance to) quorum sensing signals is necessary to prevent cells from being at a disadvantage relative to their neighbours [36]. Failure to secrete signal increases the perceived signal strength so non-participating cells are 'growth depressed' relative to their neighbours. A failure to respond to the signal entirely could delay entry into stationary phase, increasing the likelihood of death during quiescence brought on by nutrient limitation. Quorum sensing signals are typically small hydrophobic molecules, but bacterial ABC-transporter-mediated signalling is not limited to these. Rhizobium species use both polysaccharides and peptides to signal legume roots to form nodules. Both signals rely upon $\mathrm{ABC}$ transporters, and in particular one of the peptide signals is a pore-forming molecule homologous to HlyA [14]. Whether or not similar signals occur in mammalian systems is an active area of debate. Many antibacterial peptides, including some endogenous mammalian ones that resemble ABC transporter substrates, have dual roles in regulating tissue-level behaviours [70]. This suggests additional roles for $\mathrm{ABC}$ transporters as regulators of autocrine [46] and paracrine signalling in epithelia, as well as a possible role in resistance to bacterial infections.

\section{Overcoming clinical MDR}

Our main interest in MDR is that it causes treatment failure in cancer and may soon be the primary cause of failure of antibacterial therapy. We should be intellectually unsatisfied with our understanding of MDR for at least as long as it takes us to find rational ways of overcoming MDR. Progress in this area has been more limited than expected, in part due to the unexpected complication of P-gp inhibitors acting on multiple ABC transporters and, even with more specific inhibitors, the problem of enhanced toxicity at nontarget sites. In clinical trials of ABC transporter inhibitors, there has been a tendency to treat patients without adequate determination that they express the targeted resistance mechanism, which makes it harder to demonstrate clinical efficacy [64]. Nevertheless, inhibiting P-gp has demonstrated its value in some cases, most particularly in localised retinoblastoma where chemotherapy was never curative before the introduction of cyclosporine into treatment and which is now controllable by chemotherapy [7] unless MRP1-mediated resistance arises [8]. A better proof-ofprinciple could hardly be asked for, demonstrating that clinical drug resistance is finite and manageable. It will require knowledge and perseverance and perhaps unexpected new approaches based on new discoveries about the mode of action and consequences of $\mathrm{ABC}$ transporter activity and overexpression. High-throughput characterisation of gene expression and drug resistance profiles and computational mining of large datasets are now capable of discerning complex relationships between cellular phenotypes and drug responses. A correlation of drug response with $\mathrm{ABC}$ transporter expression in the NCI-60 set of tumour cell lines found both expected clusters of transporters associated with MDR and unexpected transporter/ drug resistance associations particular to certain tumour types, as well as sets of drugs to which MDR cell lines were particularly sensitive [63]. After 30 years of MDR, our understanding of this phenomenon may soon be adequate to the goal of bringing it under our control.

Acknowledgements The authors thank Maisie Lo and Melvin Kwok for helpful comments during the preparation of this manuscript. This work was supported by grants from the Canadian Institutes of Health Research, National Cancer Institute of Canada and the Canadian Cancer Society, Genome Canada and Genome British Columbia. VL is a distinguished scholar of the Michael Smith Foundation for Health Research.

\section{References}

1. Abraham EH, Prat AG, Gerweck L, Seneveratne T, Arceci RJ, Kramer R, Guidotti G, Cantiello HF (1993) The multidrug resistance (mdrl) gene product functions as an ATP channel. Proc Natl Acad Sci USA 90:312-316

2. Alemán C, Annereau JP, Liang XJ, Cardarelli CO, Taylor B, Yin JJ, Aszalos A, Gottesman MM (2003) P-glycoprotein, expressed in multidrug resistant cells, is not responsible for alterations in membrane fluidity or membrane potential. Cancer Res 63: 3084-3091

3. Ariaratnam V, Georghiou GP (1974) Carbamate resistance in Anopheles albimanus. Cross resistance spectrum and stability of resistance. Bull World Health Organ 51:655-659

4. Bech-Hansen NT, Till JE, Ling V (1976) Pleiotropic phenotype of colchicine-resistant $\mathrm{CHO}$ cells: cross-resistance and collateral sensitivity. J Cell Physiol 88:23-32 
5. Biedler JL, Riehm H (1970) Cellular resistance to actinomycin D in Chinese hamster cells in vitro: cross-resistance, radioautographic, and cytogenetic studies. Cancer Res 30:1174-1184

6. Carlsen SA, Till JE, Ling V (1976) Modulation of membrane drug permeability in Chinese hamster ovary cell mutants. Biochim Biophys Acta 455:900-912

7. Chan HS, DeBoer G, Thiessen JJ, Budning A, Kingston JE, O'Brien JM, Koren G, Giesbrecht E, Haddad G, Verjee Z, Hungerford JL, Ling V, Gallie BL (1996) Combining cyclosporin with chemotherapy controls intraocular retinoblastoma without requiring radiation. Clin Cancer Res 2:1499-1508

8. Chan HS, Lu Y, Grogan TM, Haddad G, Hipfner DR, Cole SP, Deeley RG, Ling V, Gallie BL (1997) Multidrug resistance protein (MRP) expression in retinoblastoma correlates with the rare failure of chemotherapy despite cyclosporine for reversal of Pglycoprotein. Cancer Res 57:2325-2330

9. Chang G, Roth CB (2001) Structure of MsbA from E. coli: a homolog of the multidrug resistance ATP binding cassette (ABC) transporters. Science 293:1793-1800

10. Chen Y, Pant AC, Simon SM (2001) P-glycoprotein does not reduce substrate concentration from the extracellular leaflet of the plasma membrane in living cells. Cancer Res 61:7763-7769

11. Crouzet J, Trombik T, Fraysse ÅS, Boutry M (2006) Organization and function of the plant pleiotropic drug resistance $\mathrm{ABC}$ transporter family. FEBS Lett 580:1123-1130

12. Danø K (1973) Active outward transport of daunomycin in resistant Ehrlich ascites tumor cells. Biochim Biophys Acta Biomembr 323:466-483

13. Dong J, Yang G, Mchaourab HS (2005) Structural basis of energy transduction in the transport cycle of MsbA. Science 308:10231028

14. Economou A, Hamilton WD, Johnston AW, Downie JA (1990) The Rhizobium nodulation gene nodO encodes a Ca2(+)-binding protein that is exported without $\mathrm{N}$-terminal cleavage and is homologous to haemolysin and related proteins. EMBO $\mathrm{J}$ 9:349-354

15. Eytan GD, Regev R, Oren G, Assaraf YG (1996) The role of passive transbilayer drug movement in multidrug resistance and its modulation. J Biol Chem 271:12897-12902

16. Fitzgerald ML, Moore KJ, Freeman MW (2002) Nuclear hormone receptors and cholesterol trafficking: the orphans find a new home. J Mol Med 80:271-281

17. Georghiou GP (1972) The evolution of resistance to pesticides. Ann Rev Ecolog Syst 3:133-168

18. Gerlach J, Endicott J, Juranka P, Henderson G, Sarangi F, Deuchars K, Ling V (1986) Homology between P-glycoprotein and a bacterial hemolysin transport protein suggests a model for multidrug resistance. Nature 324:485-489

19. Gottesman MM, Ling V (2006) The molecular basis of multidrug resistance in cancer: the early years of P-glycoprotein research. FEBS Lett 580:998-1009

20. Hanekop N, Zaitseva J, Jenewein S, Holland IB, Schmitt L (2006) Molecular insights into the mechanism of ATP-hydrolysis by the NBD of the ABC-transporter HlyB. FEBS Lett 580: 1036-1041

21. Higgins CF, Gottesman MM (1992) Is the multidrug transporter a flippase? Trends Biochem Sci 17:18-21

22. Higgins CF, Hiles ID, Salmond GP, Gill DR, Downie JA, Evans IJ, Holland IB, Gray L, Buckel SD, Bell AW et al (1986) A family of related ATP-binding subunits coupled to many distinct biological processes in bacteria. Nature 323:448-450

23. Higgins CF, Linton KJ (2004) The ATP switch model for ABC transporters. Nat Struct Mol Biol 11:918-926

24. Hui D, Ling V (2002) A combinatorial approach toward analyzing functional elements of the Escherichia coli hemolysin signal sequence. Biochemistry 41:5333-5339
25. Huynen MA, van Nimwegen E (1998) The frequency distribution of gene family sizes in complete genomes. Mol Biol Evol 15:583589

26. Johnson S, Armstrong JG, Gorman M, Burnett JPJ (1963) The Vinca alkaloids: a new class of oncolytic agents. Cancer Res 23:1390

27. Juliano RL, Ling V (1976) A surface glycoprotein modulating drug permeability in Chinese hamster ovary cell mutants. Biochim Biophys Acta 455:152-162

28. Jungwirth H, Kuchler K (2006) Yeast ABC transporters - a tale of sex, stress, drugs and aging. FEBS Lett 580:1131-1138

29. Kamau SW, Kramer Stefanie D, Maja Gunthert, WunderliAllenspach H (2005) Effect of the modulation of the membrane lipid composition on the localization and function of P-glycoprotein in mdr1-mdck cells. In Vitro Cell Dev Biol Anim 41:207-216

30. Karwatsky J, Lincoln MC, Georges E (2003) A mechanism for Pglycoprotein-mediated apoptosis as revealed by verapamil hypersensitivity. Biochemistry 42:12163-12173

31. Kino K, Taguchi Y, Yamada K, Komano T, Ueda K (1996) Aureobasidin A, an antifungal cyclic depsipeptide antibiotic, is a substrate for both human MDR1 and MDR2/P-glycoproteins. FEBS Lett 399:29-32

32. Koronakis V, Koronakis E, Hughes C (1989) Isolation and analysis of the C-terminal signal directing export of Escherichia coli hemolysin protein across both bacterial membranes. EMBO J 8:595-605

33. Krulwich TA, Lewinson O, Padan E, Bibi E (2005) Do physiological roles foster persistence of drug/multidrug-efflux transporters? A case study. Nat Rev Microbiol 3:566-572

34. Lam P, Wang R, Ling V (2005) Bile acid transport in sister of Pglycoprotein (ABCB11) knockout mice. Biochemistry 44:1259812605

35. Lam P, Wang R, Ling V (2005) Bile acid transport in Spgp (Bsep) knockout mice. In: Paumgartner G, Keppler D, Leuschner U, Stiehl A (eds) Bile acid biology and its therapeutic implications. Springer, Berlin Heidelberg New York, pp 91-100

36. Linares JF, Lopez JA, Camafeita E, Albar JP, Rojo F, Martinez JL (2005) Overexpression of the multidrug efflux pumps MexCDOprJ and MexEF-OprN is associated with a reduction of type III secretion in Pseudomonas aeruginosa. J Bacteriol 187:1384-1391

37. Ling V (1975) Drug resistance and membrane alteration in mutants of mammalian calls. Can J Genet Cytol 17:503-515

38. Ling V, Baker RM (1978) Dominance of colchicine resistance in hybrid CHO cells. Somatic Cell Genet 4:193-200

39. Ling V, Thompson LH (1974) Reduced permeability in CHO cells as a mechanism of resistance to colchicine. J Cell Physiol 83:103116

40. Regev R, Assaraf YG, Eytan GD (1999) Membrane fluidization by ether, other anesthetics, and certain agents abolishes Pglycoprotein ATPase activity and modulates efflux from multidrug-resistant cells. Eur J Biochem 259:18-24

41. Reuter G, Tavan J, Venter H, Shahi S, Balakrishnan L, van Veen HW (2003) The ATP binding cassette multidrug transporter LmrA and lipid transporter MsbA have overlapping substrate specificities. J Biol Chem 278:35193-35198

42. Reyes CL, Chang G (2005) Structure of the ABC Transporter MsbA in complex with ADP, vanadate and lipopolysaccharide. Science 308:1028-1031

43. Riordan JR, Ling V (1979) Purification of P-glycoprotein from plasma membrane vesicles of Chinese hamster ovary cell mutants with reduced colchicine permeability. J Biol Chem 254:1270112705

44. Robinson LJ, Roberts WK, Ling TT, Lamming D, Sternberg SS, Roepe PD (1997) Human MDR 1 protein overexpression delays the apoptotic cascade in Chinese hamster ovary fibroblasts. Biochemistry 36:11169-11178 
45. Roepe PD, Weisburg JH, Luz JG et al (1994) Novel Cl(-)dependent intracellular $\mathrm{pH}$ regulation in murine MDR 1 transfectants and potential implications. Biochemistry 33:11008-11015

46. Roman RM, Wang Y, Lidofsky SD, Feranchak AP, Lomri N, Scharschmidt BF, Fitz JG (1997) Hepatocellular ATP-binding cassette protein expression enhances ATP release and autocrine regulation of cell volume. J Biol Chem 272:21970-21976

47. Sanchez P, Linares JF, Ruiz-Diez B, Campanario E, Navas A, Baquero F, JLM (2002) Fitness of in vitro selected Pseudomonas aeruginosa nalB and $\mathrm{nfxB}$ multidrug resistant mutants. J Antimicrob Chemother 50:657-664

48. Saurin W, Hofnung M, Dassa E (1999) Getting in or out: early segregation between importers and exporters in the evolution of ATP-binding cassette (ABC) transporters. J Mol Evol 48:22-41

49. Schinkel AH, Mayer U, Wagenaar E, Mol CA, van Deemter L, Smit JJ, van der Valk MA, Voordouw AC, Spits $H$, van Tellingen O, Zijlmans JM, Fibbe WE, Borst P (1997) Normal viability and altered pharmacokinetics in mice lacking mdr1-type (drug-transporting) P-glycoproteins. Proc Natl Acad Sci USA 94:4028-4033

50. Senior AE, al-Shawi MK, Urbatsch IL (1995) The catalytic cycle of P-glycoprotein. FEBS Lett 377:285-289

51. Senior AE, Bhagat S (1998) P-glycoprotein shows strong catalytic cooperativity between the two nucleotide sites. Biochemistry 37:831-836

52. Shapiro A, Ling V (1995) Using purified P-glycoprotein to understand multidrug resistance. J Bioenerg Biomembranes 27:7-13

53. Shapiro AB, Fox K, Lam P, Ling V (1999) Stimulation of Pglycoprotein-mediated drug transport by prazosin and progesterone. Evidence for a third drug-binding site. Eur $\mathrm{J}$ Biochem 259:841-850

54. Shapiro AB, Ling V (1994) ATPase activity of purified and reconstituted P-glycoprotein from Chinese hamster ovary cells. J Biol Chem 269:3745-3754

55. Shapiro AB, Ling V (1997) Extraction of Hoechst 33342 from the cytoplasmic leaflet of the plasma membrane by P-glycoprotein. Eur J Biochem 250:122-129

56. Shapiro AB, Ling V (1997) Positively cooperative sites for drug transport by P-glycoprotein with distinct drug specificities. Eur J Biochem 250:130-137

57. Shapiro AB, Ling V (1995) Reconstitution of drug transport by purified P-glycoprotein. J Biol Chem 270:16167-16175

58. Sharom FJ (1995) Characterization and functional reconstitution of the multidrug transporter. J Bioenerg Biomembranes 27:15-22

59. Sharom FJ, Lu P, Liu R, Yu X (1998) Linear and cyclic peptides as substrates and modulators of P-glycoprotein: peptide binding and effects on drug transport and accumulation. Biochem $\mathrm{J}$ 333:621-630

60. Sheps JA, Cheung I, Ling V (1995) Hemolysin transport in Escherichia coli. Point mutants in HlyB compensate for a deletion in the predicted amphiphilic helix region of the HlyA signal. J Biol Chem 270:14829-14834

61. Sheps JA, Ralph S, Zhao Z-Y, Baillie DL, Ling V (2004) The ABC transporter gene family of Caenorhabditis elegans has implications for the evolutionary dynamics of multidrug resistance in eukaryotes. Genome Biology 5:R15

62. Skarke C, Jarrar M, Schmidt H, Kauert G, Langer M, Geisslinger G, Lotsch J (2003) Effects of ABCB1 (multidrug resistance transporter) gene mutations on disposition and central nervous effects of loperamide in healthy volunteers. Pharmacogenetics 13:651-660

63. Szakács G, Annereau JP, Lababidi S, Shankavaram U, Arciello A, Bussey KJ, Reinhold W, Guo Y, Kruh GD, Reimers M, Weinstein JN, Gottesman MM (2004) Predicting drug sensitivity and resistance: profiling $\mathrm{ABC}$ transporter genes in cancer cells. Cancer Cell 6:129-137

64. Thomas H, Coley HM (2003) Overcoming multidrug resistance in cancer: an update on the clinical strategy of inhibiting pglycoprotein. Cancer Control 10:159-165

65. Ubukata K, Itoh-Yamashita N, Konno M (1989) Cloning and expression of the norA gene for fluoroquinolone resistance in Staphylococcus aureus. Antimicrob Agents Chemother 33:15351539

66. Ueda K, Okamura N, Hirai M, Tanigawara Y, Saeki T, Kioka N, Komano T, Hori R (1992) Human P-glycoprotein transports cortisol, aldosterone, and dexamethasone, but not progesterone. J Biol Chem 267:24248-24252

67. Uhr M, Holsboer F, Muller MB (2002) Penetration of endogenous steroid hormones corticosterone, cortisol, aldosterone and progesterone into the brain is enhanced in mice deficient for both mdrla and mdr1b P-glycoproteins. J Neuroendocrinol 14:753-759

68. Urbatsch IL, al-Shawi MK, Senior AE (1994) Characterization of the ATPase activity of purified Chinese hamster P-glycoprotein. Biochemistry 33:7069-7076

69. van Veen HW, Venema K, Bolhuis H, Oussenko I, Kok J, Poolman B, Driessen AJ, Konings WN (1996) Multidrug resistance mediated by a bacterial homolog of the human multidrug transporter MDR1. Proc Natl Acad Sci USA 93:10668-10672

70. Vyoral D, Petrak J (2005) Hepcidin: a direct link between iron metabolism and immunity. Int J Biochem Cell Biol 37:1768-1773

71. Wang R, Lam P, Liu L, Forrest D, Yousef IM, Mignault D, Phillips MJ, Ling V (2003) Severe cholestasis induced by cholic acid feeding in knockout mice of sister of P-glycoprotein. Hepatology 38:1489-1499

72. Whitehead GB (1959) Pyrethrum resistance conferred by resistance to DDT in the blue tick. Nature 184:378-379

73. Yu EW, McDermott G, Zgurskaya HI, Nikaido H, Koshland DE Jr (2003) Structural basis of multiple drug-binding capacity of the AcrB multidrug efflux pump. Science 300:976-980

74. Zhang F, Greig DI, Ling V (1993) Functional replacement of the hemolysin A transport signal by a different primary sequence. Proc Natl Acad Sci USA 90:4211-4215

75. Zhang F, Sheps JA, Ling V (1993) Complementation of transport deficient mutants of $E$. coli $\alpha$-hemolysin by second-site mutation in the transporter HlyB. J Biol Chem 268:19889-19895

76. Zhang F, Yin Y, Arrowsmith CH, Ling V (1995) Secretion and circular dichroism analysis of the C-terminal signal peptides of HlyA and LktA. Biochemistry 34:4193-4201

77. Zhao Z-Y, Sheps JA, Ling V, Fang LL, Baillie DL (2004) Expression analysis of $\mathrm{ABC}$ transporters reveal differential functions of tandemly duplicated genes in Caenorhabditis elegans. J Mol Biol 344:409-417

78. Zhu BT (1999) A novel hypothesis for the mechanism of action of P-glycoprotein as a multidrug transporter. Mol Carcinog 25: $1-13$

79. Zhu H, Cai C, Chen J (2004) Suppression of P-glycoprotein gene expression in Hs578T/Dox by the overexpression of caveolin-1. FEBS Lett 576:369-374 